\title{
Nesbitt's Paradox resolved? Stress and arousal modulation during cigarette smoking
}

\author{
ANDREW C. PARROTT \\ Department of Psychology, University of East London, UK
}

\begin{abstract}
Nesbitt's Paradox states that cigarette smoking generates physiological and psychological changes which are normally incompatible, namely increased arousal together with decreased stress. This review confirms these changes, but shows that they are dependent upon various factors, particularly the degree of nicotine deprivation. Thus the relaxant properties of smoking reflect the relief of irritability which develops between cigarettes. The deleterious mood effects of abstinence explain why smokers suffer more daily stress than non-smokers, and become less stressed when they quit smoking. Deprivation reversal also explains much of the arousal data, with deprived smokers being less vigilant and less alert than non-deprived smokers or non-smokers. Nicotine can, however, display genuine stimulant properties, although due to repeated abstinence effects the average arousal level of smokers is generally similar to non-smokers. Mood normalization also explains why nicotine is so addictive, with regular smokers needing nicotine just to "function" normally. Finally, Nesbitt's Paradox also assumes that arousal and emotionality are associated with each other. Yet factor analysis of mood and personality questionnaires shows that these two dimensions are statistically independent, with the stress and arousal changes during smoking also generally uncorrelated. Nesbitt's Paradox is therefore not actually a paradox; it never was a paradox.
\end{abstract}

\section{Introduction}

In 1973 Stanley Schachter described: "Nesbitt's Paradox ... a perverse concatenation of data which simply doesn't make sense" (Schachter, 1973, p. 148). The core of the Paradox was that while smoking leads to sympathetic arousal, in psychological terms smokers report feelings of relaxation: "The physiological and psychological effects of smoking a cigarette are seemingly in contradiction to each other. When smokers smoke, their level of physiological arousal goes up, while they report themselves as calmer and more relaxed" (Nesbitt, 1973, p. 137). The essence of Nesbitt's Paradox is that tobacco smoking seems to be both stimulating and relaxing.

Other research groups confirmed these smoking motives (Ikard, Green \& Horn, 1969; McKennell, 1970), with separate factors for stress control or "sedative smoking", and the maintenance of alertness or "stimulant smoking" (Russell, Peto \& Patel, 1974; West \& Russell, 1985; Shiffman, 1993). This led to a subtle

Correspondence: Andrew C. Parrott, Department of Psychology, University of East London, London E15 4LZ, UK. Tel: + 44 (0)1815907722, ext 4505; fax: + 44(0)1818493697; e-mail: andy2@uel.ac.uk.

Submitted 29th January 1997; initial review completed 11th April 1997; final version accepted 14 th July 1997. 
reformulation of the Paradox, into the contrast between contradictory psychological reasons for smoking:

Nicotine is a stimulant, its effect being to activate neural systems. Hence there is no difficulty in accepting verbatim one of the smoker's stated reasons for smoking, namely to be stimulated. But there is considerable difficulty in reconciling the stimulant properties of nicotine with the smoker's statement that he seeks the calming, relaxing effects of smoking. Why, when under stress, does the smoker seek more stimulation? It is my belief that when we resolve the Nesbitt Paradox we will have identified the primary reinforcing mechanism in cigarette smoking (Dunn, 1978, p. 19).

Schachter (1978) proposed an explanation for Nesbitt's Paradox based upon changes in the acidity of the urine during stress, but subsequent research failed to confirm this (Rosenberg et al., 1980; Pomerleau \& Pomerleau, 1990). Gilbert (1979) concluded that the empirical data on the Paradox were inconsistent or unclear. Gilbert (1995) reviewed the mood effects of smoking again, but did not re-examine the Paradox. Others, however, have noted that Nesbitt's Paradox remains unsolved. Warburton (1988, p. 369) stated that nicotine was unique because it combined performance enhancement with anxiety reduction. Ney \& Gale (1989, p. 7) commented upon the enduring controversy that smoking seemed to either arouse or tranquillize. Pomerleau \& Pomerleau (1990, p. 227) concluded: "The ability of nicotine to produce both arousal and sedation poses a special challenge to research."

There are three core aspects to Nesbitt's Paradox: the effects of smoking upon arousal; the effects of smoking upon stress; and the interrelationship between these changes. Each topic will be analysed separately. Stress and arousal are broad constructs, covering a diverse array of phenomena. This paper will follow the definitions from the original articles (Nesbitt, 1973; Schachter, 1973), and largely maintained since (Church, 1989; Gilbert, 1995). Arousal is an energetic construct, reflecting feelings of alertness, and standard EEG characteristics (Church, 1989). High arousal is generally accompanied by fast and efficient information pro- cessing, although excessive arousal may be counter-productive, as described in the YerkesDodson inverted- $U$ curve (Parrott, 1992, Sherwood, 1993; Heishman, Taylor \& Henningfield, 1994). Stress is an emotional construct, reflecting feelings of anxiety and tension, and poor coping skills, particularly under threat (Gilbert \& Wesler, 1989; Pomerleau \& Pomerleau, 1991; Gilbert, 1995).

The following perspectives will be taken in an attempt to resolve the Paradox. First, it will be suggested that the positive changes noted by Nesbitt and Schachter (relaxation and alertness), largely reflect reversal of the negative effects of abstinence (irritability and impaired concentration). A core question will be whether nicotine generates any real psychobiological benefits, in addition to the reversal of abstinence effects (West, 1993). Secondly, Nesbitt (1973) suggested that arousal is generally accompanied by stress, and tiredness with relaxation. However, it will be shown instead that they are basically orthogonal and independent.

\section{Cigarette smoking and arousal}

Schachter (1973) listed several lines of evidence to indicate the arousing effects of smoking: heightened cardiovascular activity, increased epinephrine (adrenaline) excretion, EEG indices of heightened arousal, and animal data showing that nicotine had CNS stimulant properties (Nesbitt, 1973; Schachter, 1973). These changes have been widely replicated, and it is generally acknowledged that smoking is often arousing (Church, 1989; Gilbert, 1995). Task performance also tends to be increased after smoking, in comparison with continued abstinence (Wesnes \& Warburton, 1983; Revell, 1988; Hasenfrantz et al., 1989; Parrott \& Roberts, 1991; Sherwood, 1993; Parrott et al., 1996b). The relationship between arousal and performance is basically linear, with increased arousal leading to better performance (fig. 3 in Parrott, 1992); although full-strength cigarettes can sometimes boost arousal past the level for optimal performance (fig. 2 in Parrott, 1992; Wesnes \& Warburton, 1983). Tobacco chewing, nicotine tablets or nicotine gum can also increase arousal and/or performance, again in comparison with nicotine deprivation (Wesnes \& Warburton, 1983; Keenan, Hatsumaki \& Anton, 1989; Parrott \& Winder, 1989; Snyder \& Henningfield, 1989). 
This arousal increase occurs when nicotine is given to deprived smokers, and nicotine deprivation generally leads to decreased arousal. In a review of the smoking/EEG literature, Church (1989, p. 127) concluded: "Smoking deprivation has been followed by EEG signs of sedation, smoking by EEG signs of arousal." Thus, Knott \& Venables (1977) found that abstaining smokers had less activated EEGs than non-deprived smokers. A similar pattern occurs in the performance literature, with smokers generally showing better task performance than deprived smokers (for reviews see: Wesnes \& Parrott, 1992; Sherwood, 1993; Heishman et al., 1994). Therefore, a performance improvement is often indicative of an arousal increase, as long as performance is not pushed past the peak of the Yerkes-Dodson inverted- $U$ curve (Parrott, 1992). Deprived tobacco chewers also display lower vigilance performance than non-deprived tobacco chewers (Keenan et al., 1989). The opposing effects of smoking and deprivation raise the question of whether smoking generates a genuine arousal gain, or simply reverses abstinence effects (Surgeon General, 1988, p. 393). This question is not easy to resolve, because the "normal" arousal level for each smoker is unknown, following years of chronic nicotine use. Indirect evidence can, however, be provided from non-smokers. Knott \& Venables (1977) reported that overnight deprived smokers had less activated EEGs than non-smokers or current smokers, whereas the EEG profiles of current smokers were similar to non-smokers. Deprived smokers also tend to display lower levels of cognitive task performance than both non-deprived smokers and non-smokers, whereas the performance of these latter groups are generally similar (Heimstra et al., 1967; Wesnes \& Parrott, 1992; Sherwood, 1993; Heishman et al., 1994). Keenan et al. (1989) found similar task performance levels in tobacco chewers and non-chewers, whereas deprived tobacco chewers were significantly impaired in comparison to both groups. Overall, therefore, tobacco deprivation generally leads to reduced arousal, whereas tobacco use generally leads to normal/average arousal.

Differences in baseline arousal levels can also affect arousal changes. Perkins et al. (1992a) divided smokers into two subgroups on the basis of alertness self-ratings at baseline. Subjects with low baseline arousal reported a significant in- crease in arousal following either smoking or nasal nicotine. However, those with higher baseline arousal reported no change in arousal, after either smoking or the nasal nicotine. Parrott (1994a) divided 105 smokers into four subgroups, according to scores on the Smoking Motivation Questionnaire stimulant subscale. High stimulant smokers reported the greatest increase in arousal post-smoking, but the lowest arousal pre-smoking. The arousal levels of all subgroups after-smoking were very similar. Thus the effects of smoking upon arousal seem to reflect largely a process of mood normalization, with deprived smokers reporting low arousal, and non-deprived smokers displaying similar arousal to non-smokers (Parrott et al., 1996; Jones \& Parrott, 1997). This mood normalization is also consistent with the wording of some of the questions on stimulant smoking: "I smoke in order to keep myself from slowing down" (Ikard et al., 1969); "Smoking keeps me going when I am tired" (Russell et al., 1974). Schachter (1973, p. 148) also noted that smokers did not report being "stimulated" or "bucked-up" by cigarettes. However, other questions are suggestive of a real alertness gain: "I get a definite lift and feel more alert while smoking" (Russell et al., 1974). The issue of whether nicotine can sometimes generate true stimulation is addressed again later.

\section{Cigarette smoking and stress}

Nesbitt (1973) noted that one of the most frequently given reasons for smoking was stressreduction, with $80 \%$ of smokers using cigarettes when feeling stressed or angry (Ikard et al., 1969). Schachter (1978, p. 209) noted: "Smokers widely report that they smoke more when they are tense or anxious and they also report that smoking calms them". Schachter and Nesbitt were concerned that these findings were based upon questionnaire surveys, so they measured emotional reactivity using an objective laboratory task. Volunteers were given incremental levels of electric shock, and asked to report when they became too painful to endure. Chronic smokers had significantly higher endurance thresholds when smoking than not-smoking, with high-nicotine cigarettes leading to higher endurance thresholds than low-nicotine cigarettes (Nesbitt, 1973; Schachter, 1973). The stress-relieving effects of smoking have been confirmed with a range of questionnaires, mood 
scales and stress-induction tasks (Russell et al., 1974; Schechter \& Rand, 1974; Gilbert, 1979; Silverstein, 1982; Speilberger, 1986; Warburton, Revell \& Walters, 1988; Gilbert \& Wesler, 1989; Pomerleau \& Pomerleau, 1990, 1991; Warburton, 1992; West, 1993). The role of nicotine in mood modulation has also been demonstrated; nicotine chewing-gum reduces the severity of abstinence effects (Hughes, Higgins \& Hatsukami, 1990), and is used by quitting smokers for both stress control and arousal control (Parrott \& Craig, 1995).

This stress-relief raises the same question noted earlier for arousal: does it reflect a genuine gain, or the simple reversal of abstinence effects? This is again difficult to answer, since the "normal" (drug-free) level of emotional functioning for each cigarette smoker is unknown. However, indirect evidence can be provided by non-smokers. If nicotine is an effective anxiolytic, then smokers should be less stressed than non-smokers (assuming similar personality profiles; see below), and they should certainly suffer from increased stress if they quit smoking. Against the first prediction, questionnaire surveys find that smokers report high levels of everyday stress. Warburton, Revell \& Thompson (1991) noted that heavy smokers reported above-average levels of stress and neuroticism, replicating findings from the same laboratory 12 years earlier. In the UK Health and Lifestyle Survey of 9000 participants, significantly more smokers admitted to: "Feeling constantly under strain" than either non-smokers or former smokers (Warburton et al., 1991, p. 623). Jones \& Parrott (1997) found significantly higher stress ratings in smokers than non-smokers, working both day-shifts and night-shifts. West (1992, p. 166) similarly concluded: "Against the anxiety reduction theory is the finding that smokers do not present as less anxious than non-smokers. Indeed, in surveys, they emerge as significantly more anxious overall". Warburton (1988) suggested that these high stress levels were because smokers were neurotic; indeed many surveys have noted an association between smoking and neuroticism (Gilbert, 1995, p. 152). However, there is no empirical evidence that smoking leads to a genuine stress reduction, which still leaves smokers feeling more stressed than non-smokers. An alternative explanation is that smoking directly causes stress (Parrott, 1995b). According to this model, regular smokers tend to become anxious and nervous when they have not smoked recently; this causes their above-average levels of daily stress. The readiness with which negative moods develop during abstinence may also be related to trait emotionality; this could explain the association between smoking and neuroticism (Gilbert, 1995, p. 152).

The clearest empirical test of these alternative explanations is to monitor the stress levels of smokers who quit smoking. If smoking aids with stress control, then stress levels should rise following cessation (Warburton, 1988, 1992), but if cigarette smoking is exacerbating stress, then stress levels should decrease when smokers quit (Parrott, 1995b). Several longitudinal cessation studies have monitored feelings of stress over time, and they find reduced stress after quitting. Hughes (1992) found a brief period of increased anxiety, irritability and restlessness, 2 days and 7 days after-quitting, but these negative moods returned to baseline 14 days post-quitting, then decreased further 30,90 and 180 days afterwards. Cohen \& Lichtenstein (1990) monitored self-perceived stress prior to quitting and 1, 3 and 6 months post-cessation. Successful quitters reported a steady decrease in stress over time, whereas those who failed to quit reported high stress at each time point. Both groups had similar stress scores at (smoking) baseline; thus, it was not just the low-stress individuals who managed to quit. Two further longitudinal stress/ cessation studies have confirmed that smoking cessation leads to significantly reduced feelings of stress (Carey et al., 1993; Parrott, 1995b).

It seems therefore that tobacco use does not confer real benefits in terms of stress control. This is also consistent with the effects of intravenous nicotine in non-smokers, who report increased feelings of tenseness, depression and confusion (Newhouse et al., 1990). Smokers therefore need frequent supplies of nicotine simply to maintain normal moods, and suffer from stress and irritability when they have not smoked recently (Parrott, 1994a). Schachter (1978, p. 210) offered this conclusion many years ago: "It would appear then that smoking is not anxiety reducing but, rather, that no smoking or insufficient nicotine is for the heavy smoker, anxiety increasing." Silverstein (1982, p. 949) similarly noted that deprived smokers experienced withdrawal symptoms which they interpreted as anxiety, and nicotine replenishment relieved these deleterious moods and so restored 
normality. Smokers therefore suffer a source of stress not encountered by non-smokers: acute nicotine depletion (Parrott, 1995b). When they successfully quit smoking they no longer experience this, and their daily moods improve (Cohen \& Lichtenstein, 1990; Carey et al., 1993; Hughes, Higgins \& Bickel, 1994; Parrott, 1995b).

\section{Mood changes as the reversal of abstinence effects}

The essence of the current explanation is that the psychological "gains" experienced while smoking represent the reversal of abstinence effects. In order to evaluate this model critically, the abstinence syndrome needs to be described more fully. Tobacco abstinence symptoms are well documented, with feelings of stress, anger, irritability, concentration difficulty, hunger and cigarette craving (Hughes et al., 1990, 1994). However, their development over time has not been fully described: "There is little data on the time course of nicotine withdrawal symptoms" (West, Hajek \& Belcher, 1989, p. 143; Foulds, 1994). For instance, changes in EEG profiles over a period of abstinence, do not seem to have been studied empirically (Church, 1989). There are, however, some data on cognitive performance changes. Snyder, Davis \& Henningfield (1989) reported a pattern of increasing performance decrements over the first day of abstinence, but all comparisons were with pretest baseline (there was no control group), so that learning, fatigue and circadian factors were all confounded with withdrawal effects. Parrott et al. (1996) compared attentional task performance after 2,6 and 24 hours of abstinence, with equivalent periods of normal smoking, and found significant decrements at each deprivation period. Sherwood (1993, p. 157) noted in a review: "Generally the results support a finding of impaired psychomotor function among smokers after three or more hours of tobacco abstinence."

Withdrawal effects have therefore been empirically demonstrated following 2 or 3 hours without nicotine. However, studies of normal smoking behaviour have found more rapid psychological changes. Warburton (1992) monitored mood ratings after each inhalation, to two cigarettes smoked 30 minutes apart. Significant improvements were found as the first cigaretteof-the-day was smoked, compared to both base- line and sham smoking. These mood ratings then deteriorated during the 30-minute period between cigarettes, but improved again as the second cigarette was smoked. Parrott (1994a) also noted frequent mood fluctuations, with improved self-ratings of stress and arousal immediately after smoking, followed by corresponding deterioration between cigarettes. West \& Jarvis (1986) noted a similar pattern of psychomotor performance reversals, contingent upon nicotine administration every 60 minutes. Perkins et al. (1992b, p. 304) monitored mood changes in regular smokers undertaking two laboratory tasks, and found a brief period of reduced stress on the high stress task: "However, this stress reduction ... largely disappeared by the midpoint of each trial, nearly 10 minutes after smoking." This pattern of frequent psychological reversals also fits with cigarette consumption rates, since regular smokers tend to light a new cigarette every 30-60 minutes.

These changes in stress and arousal during smoking are summarized in Fig. 1. The essence of this model is that regular smokers experience deleterious psychological changes between cigarettes, but positive changes during smoking. Three variants of the model are shown. Figure 1a represents the nicotine resource model, with nicotine generating real psychological gains (Warburton, 1988, 1992). Figure 1c represents the deprivation reversal model, where nicotine simply reverses abstinence effects (Schachter, 1978; Silverstein, 1982). Figure 1b comprises an intermediate model, where nicotine generates some positive changes, in addition to the reversal of abstinence effects (West, 1993).

The stress data are largely consistent with the deprivation reversal model, with mood improvements during smoking representing the relief of abstinence symptoms (Fig. 1c). Smokers report normal moods when they have just smoked, but increased tension and irritability when they have not smoked. This raises the question of whether there are any situations under which nicotine generates real gains in stress control; but this does not seem to occur. There are no clear or consistent demonstrations of genuine stress improvements in active smokers, compared to nonsmokers. Indeed, the poor average moods reported by smokers, combined with their statements that cigarettes are relaxing, has often been noted as a conundrum (Gilbert \& Wesler, 1989; Pomerleau \& Pomerleau, 1991). 


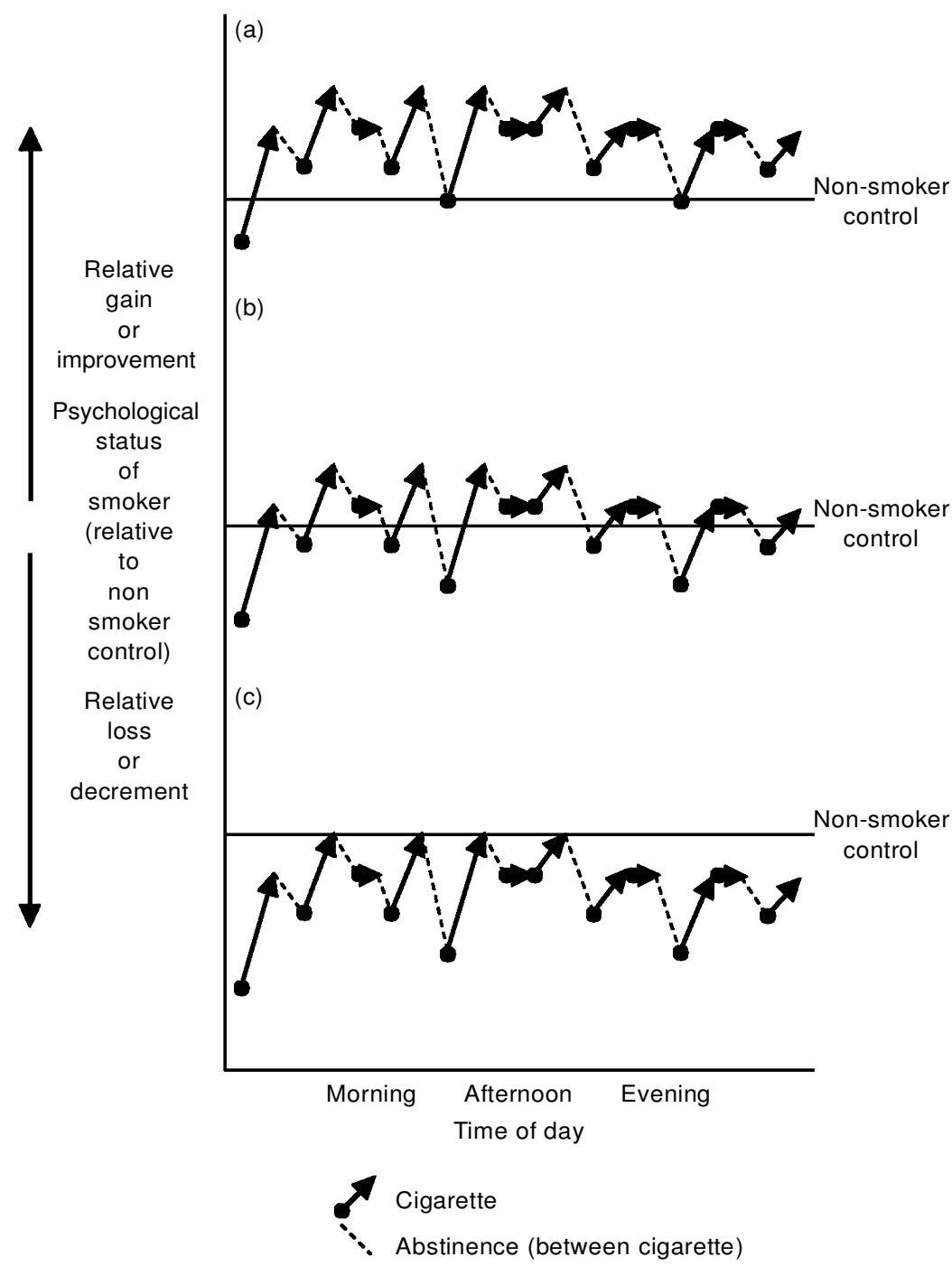

Figure 1. Three models of mood modulation during cigarette smoking: nicotine resource model (a), deprivation reversal model $(c)$ and combined resource/deprivation model (b). (Note: the profile of mood change drawn schematically here represents an individual smoker, based on Parrott, 1994a. The daily mood profile is constant throughout, with each model differing only in the position of non-smokers. A psychological gain could indicate either higher arousal or less stress.)

When we turn to arousal the situation is more complex, although deprivation reversal is certainly the key element in any explanation (Fig. 1c). Thus, deprived smokers generally display lower levels of arousal than non-deprived smokers, while the arousal levels of active smokers are generally similar to non-smokers (Heishman, Taylor \& Henningfield, 1994). However, it has often been noted that nicotine has neurochemical and sympathomimetic actions indicative of
CNS stimulation (Nesbitt, 1973; Schachter, 1973; Russell et al., 1974; Wesnes \& Warburton, 1983). Increased arousal or faster task performance, has been noted when nicotine is given to tobacco-naive subjects, or Alzheimer's disease patients (Wesnes \& Warburton, 1983; West \& Jarvis, 1986; Sahakian et al., 1989; Newhouse et al., 1990). Nicotine also reverses the cortical sedation induced by scopolamine (Wesnes \& Revell, 1984) and chlorpromazine (Swett, 1974). 
The sleep of smokers is also consistent with CNS stimulation. Regular smokers have significantly poorer sleep than non-smokers (Wetter \& Young, 1994), while 6 months after quitting former smokers display significant improvements in sleep architecture (Wolter et al., 1997).

There is also some evidence that "chain smokers" who constantly inhale nicotine $(+60$ cigarettes/day), experience increased tonic arousal (Brown, 1973). With average smokers (15-40 cigarettes/day) there are occasional reports of increased arousal, although these studies generally suffer from inadequate controls. West \& Hack (1991) found significantly better performance in regular and occasional smokers using tobacco in comparison with a herbal mixture; this has been quoted as indicating a genuine arousal increase with nicotine (Sherwood, 1993, p. 178), but West \& Hack (1991) did not have a control group of non-smokers, thus is not possible to assess whether the improvement represented a true gain. Other studies have used "minimally deprived" smokers as controls (regular smokers who have been barred from smoking for 2 or 3 hours; Sherwood, 1993). However, the assumption that this period without nicotine will not have reduced arousal is probably incorrect (see previous section on abstinence; also West \& Jarvis, 1986). The final line of reasoning for nicotine having stimulant actions is that while arousal tends to covary with smoking behaviour, the average daily arousal of smokers is similar to non-smokers. This suggests that slight arousal gains on smoking are followed by slight arousal losses between cigarettes; this would result in similar mean arousal levels for active smokers and non-smokers (Fig. 1b). It also explains how arousal gains can occur with "chain smokers" (Brown, 1973). Overall, therefore, while the arousal data are best explained by the deprivation reversal model (Fig. 1c); there is evidence that elements of arousal gain may also occur (Fig. 1b).

\section{Stress and arousal modulation: are they re- lated or independent?}

The essence of Nesbitt's Paradox is that smoking leads to a simultaneous increase in arousal and decrease in stress. This is paradoxical because "sedation" is affected in contradictory ways, i.e. cortical sedation is reduced while emotional sedation is increased. This section will examine the empirical evidence for these changes. It will also debate whether cortical arousal and emotionality are normally linked together, or whether they should be seen as independent. Nesbitt (1973) reported a significant positive correlation between pulse rate change and endurance threshold increment in cigarette smokers $(r=+0.38, p<0.05)$; hence a correspondence between increased cardiovascular arousal and decreased stress was established. However, this pattern was not found with non-smokers, where the equivalent correlation value was negative $(r=-0.22$, non-significant). Shiffman \& Jarvik (1984) attempted to replicate Nesbitt's study, but were unable to determine the shock endurance threshold for most subjects. However, they did find a significant negative correlation between physiological arousal and emotional relaxation $(r=-0.56, p<0.04)$. Perkins et al. (1992b, p. 307) found a general increase in cardiovascular arousal and occasional reductions in stress in subjects performing laboratory tasks, but the correlation between these stress and arousal changes was non-significant:

On the surface, these results tend to support the notion of simultaneous effects of tobacco smoking on reducing subjective stress while increasing cardiovascular arousal, consistent with the nicotine paradox. However, careful evaluation of these results indicates that these seemingly paradoxical effects appear to be unrelated, or dissociated.

Parrott (1994a) also found that the stress and arousal changes during smoking were uncorrelated $(r=+0.07$, non-significant). Warburton et al. (1988, p. 360) monitored mood self-ratings as deprived smokers smoked a single cigarette. They found a gradual increase in feelings of contentment and relaxation over successive puffs, but: "Within the alertness factor we found little effect of smoking, perhaps because the subjects were already close to maximum alertness to do the task." In summary, Nesbitt (1973) showed a positive correlation between stress and arousal, Shiffman \& Jarvik (1984) generated a negative correlation, but three other studies have shown them to be uncorrelated (Warburton, 1988; Perkins et al., 1992b; Parrott, 1994a). Overall, therefore, changes in stress and arousal during smoking seem to be generally independent. 


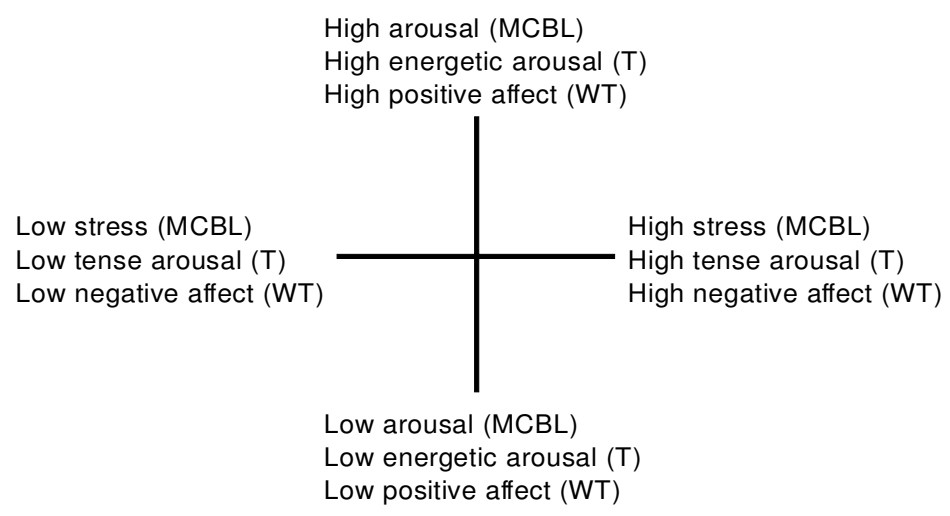

Figure 2. Two-factor structural model of mood, after Mathews et al. (1990). (Note: the two mood factors are statistically independent.) $M C B L=$ Mackay et al. (1978); $T=$ Thayer (1978); WT $=$ Watson $\&$ Tellegen (1985).

This raises the wider question of whether these psychological functions normally covary. Nesbitt (1973, p. 137) proposed that they are generally linked, quoting Schachter's (1964) study of ephedrine, placebo and chlorpromazine injections in normal volunteers. The CNS stimulant ephedrine led to increased arousal and emotionality, whereas the antipsychotic drug chlorpromazine led to reduced arousal and emotionality. One problem is that these drugs have a broad spectrum of neurochemical effects, and more selective psychoactive compounds can generate independent changes in stress and arousal. For instance, the benzodiazepine clobazam leads to anxiety reduction without cortical sedation or psychomotor slowing (Hindmarch, 1985). In an equivalent fashion, 3,4-methylenedioxymethamphetamine (MDMA) leads to greater energy and alertness, without increasing stress (Davison \& Parrott, 1997). Closer examination of Schachter's (1964) classic study also lends doubt to the supposed link between emotion and arousal: "When subjects were informed that the injection might produce physiological arousal symptoms, they behaved significantly less emotionally than subjects who were not informed" (Nesbitt, 1973, p. 143). In that situation, heightened arousal was accompanied by decreased emotionality.

Further evidence for the independence of arousal and emotion comes from mainstream (non-psychopharmacological) mood research. Mathews et al. (1990) investigated the interrelationships between the mood scales from several standardized questionnaires in a study of 388 normal volunteers, and empirically confirmed the two primary dimensions of stress (tense arousal, or negative affect), and arousal (energetic arousal, or positive affect; Fig. 2). Using factor analysis with oblique final rotation, these dimensions were shown to be uncorrelated $(r=+0.03$, non-significant; Mathews et al., 1990 , p. 22). Thus stress and arousal are independent mood factors (Mackay et al., 1978). Personality research has come to a similar conclusion. Cattell's 16PF questionnaire is based upon 16 primary factors, which factorize into independent second order factors, including exvia and anxiety (Cattell \& Kline, 1977). The two core factors in Eysenck's personality theory, extraversion and neuroticism, are also statistically uncorrelated. In theoretical terms, extraversion and exvia are indices of cortical arousal, whereas neuroticism and anxiety are reflections of emotionality and stressfulness (Cattell \& Kline, 1977). Overall, therefore, mainstream mood and personality research, has consistently demonstrated the statistical independence of stress and arousal (Fig. 2).

\section{Psychobiology of nicotine addiction}

The essence of the current model is that nicotine depletion can lead to a range of negative psychological states: nervousness, irritability, depression, poor concentration and impaired task performance. Cigarette reinstatement then generates feelings of relaxation, pleasure and improved concentration as normal psychological 
functioning is restored. The psychoactive effects of smoking are rapid, with mood and performance gains accompanying each nicotine boost to the brain 7-10 seconds post-inhalation (Revell, 1988; Benowitz, 1990; Warburton, 1992). In contrast the deleterious effects of abstinence develop more slowly, over a time course which may be quite variable. Environmental demands, past smoking habits and general expectations may influence abstinence effects, probably to varying extents with different types of smoker. For instance, heavy regular smokers may be mainly affected by pharmacokinetic factors (e.g. plasma nicotine; Benowitz, 1990), and thus develop abstinence effects at regular intervals. Occasional smokers or "chippers" (Shiffman et al., 1994) seem to be affected mainly by situational factors, and develop cravings only in environments where they normally smoke. Most regular smokers probably follow an intermediate pattern, with pharmacokinetic factors (time since last cigarette), modulated by habits and situational demands.

This model has learning theory implications. Mood modulation will be conditioned over time, so that abstinence will become associated with feelings of irritability and poor concentration. Not only will abstinence become a state to avoid, but withdrawal symptoms become more unpleasant as they increase in severity over time. The regular intake of nicotine will then be positively conditioned, both by precluding the development of abstinence effects and by reversing them once they have started. Thus the "bite" of the noxious tar and carbon monoxide at the back of the throat, becomes conditioned as "satisfying". Fant, Shuh \& Stitzer (1995) have shown that the satisfaction rating for each cigarette is a direct function of the duration of prior abstinence. The greatest reward therefore occurs with the first cigarette of the day, although other cigarettes may also generate mood relief, particularly following longer periods of abstinence (Warburton, 1992; Parrott, 1994b, 1995a). These changes may also be quite variable. Some cigarettes will be associated with stress and arousal relief, while others may lead to changes in stress alone, or alertness alone (Parrott, 1994a). Many cigarettes will not be accompanied by change in either mood state, but will be smoked for other reasons: social, psychomotor, automatic (Russell et al., 1974), or nicotine preloading (before entering no-smoking environments). Learning theory states that partial reinforcement leads to stronger conditioning than continuous reinforcement. These intermittent mood changes thus become strongly conditioned and resistant to extinction, so that even denicotinized cigarettes are satisfying (Westman, Behn \& Rose, 1996). It also explains why relapse during smoking cessation is most likely under situations of high stress, or when needing to work and concentrate (Shiffman, 1982). Thus quitting smokers report significantly heightened negative affect and/or low arousal just before a relapse (Shiffman et al., 1996).

The Surgeon General (1988) raised three main criteria for defining the drug addictiveness: compulsive use, psychoactivity and drugreinforced behaviour. These three criteria are all central to the present model. Cigarette smoking is seen as a compulsive and repetitive drugtaking behaviour, with the regularity of nicotine intake being a direct function of its mood normalization actions. Furthermore, although there is individual variation in smoking patterns, they link together in a meaningful way. Daily cigarette consumption, the early initiation of smoking each morning, and the severity of self-rated nicotine addiction, each correlate with the degree of mood modulation (Parrott, 1994a). Heavy smokers not only consume more cigarettes than light smokers, but develop poorer moods between cigarettes and achieve greater mood normalization post-smoking (Table 1); it is therefore not surprising that they report being more strongly addicted (Parrott, 1994a).

Robinson \& Pritchard (1992) argued against the Surgeon General's (1988) conclusion that nicotine was addictive, suggesting instead that: "Smokers use cigarettes primarily as a tool or resource that provides them with needed psychological benefits: increased mental alertness, anxiety reduction, coping with stress. This resource hypothesis stands as a major alternative to the addiction hypothesis" (Robinson \& Pritchard, 1992, p. 398). The nicotine resource model predicts that smokers should be less stressed and more alert than non-smokers, but there is little empirical support for this (see earlier). The resource model also predicts that smokers will suffer without nicotine: "Smoking is a mood modifier ... people miss these benefits when they stop smoking" (Warburton, 1992, p. 57; Warburton et al., 1988); it cannot explain why smokers become less stressed when they quit (Cohen 
Table 1. Pre-and post-smoking self-rated stress levels for different $S M Q$ sedative subgroups, and arousal levels for the $S M Q$ stimulant subgroups (after Table 1 in Parrott, 1994a)

\begin{tabular}{|c|c|c|c|c|c|c|}
\hline \multirow[b]{2}{*}{ Subject characteristics } & \multicolumn{5}{|c|}{ SMQ sedative subscale score } & \multirow{2}{*}{$\begin{array}{l}\text { Monotonic } \\
\text { function }\end{array}$} \\
\hline & $0-2$ & $3-4$ & $5-6$ & $7-8$ & 9 & \\
\hline$N$ (male/female) & $6(5 / 1)$ & $23(7 / 16)$ & $17(6 / 11)$ & $30(13 / 17)$ & $29(9 / 20)$ & \\
\hline Age (years) & $27.7 \pm 5.8$ & $29.6 \pm 13.0$ & $26.9 \pm 9.3$ & $29.0 \pm 12.7$ & $35.1 \pm 16.9$ & \\
\hline Cigarettes (day) & $9.8 \pm 4.2$ & $10.3 \pm 6.0$ & $10.1 \pm 5.9$ & $12.3 \pm 6.0$ & $15.1 \pm 4.9$ & $\star \star$ \\
\hline \multicolumn{7}{|l|}{ Stress } \\
\hline Pre-cigarette & $4.7 \pm 1.0$ & $5.3 \pm 1.1$ & $5.2 \pm 1.0$ & $5.2 \pm 1.0$ & $5.7 \pm 1.0$ & $t$ \\
\hline Post-cigarette & $4.8 \pm 1.8$ & $4.8 \pm 1.3$ & $4.5 \pm 1.2$ & $4.3 \pm 0.9$ & $4.5 \pm 1.1$ & \\
\hline \multirow[t]{2}{*}{ Pre-post difference } & $0.1 \pm 1.2$ & $-0.5 \pm 1.0$ & $-0.7 \pm 1.4$ & $-0.9 \pm 0.8$ & $-1.2 \pm 1.3$ & $\star \star$ \\
\hline & \multicolumn{5}{|c|}{ SMQ stimulant subscale score } & \\
\hline Subject characteristics & $0-2$ & $3-4$ & $5-6$ & $7-9$ & & function \\
\hline$N$ (male/female) & $34(19 / 15)$ & $32(10 / 22)$ & $28(10 / 18)$ & $11(1 / 10)$ & & \\
\hline Age (years) & $33.5 \pm 14.9$ & $29.1 \pm 13.8$ & $27.4 \pm 11.3$ & $32.1 \pm 12.7$ & & \\
\hline Cigarettes (day) & $11.3 \pm 6.3$ & $10.9 \pm 5.5$ & $12.9 \pm 5.5$ & $16.6 \pm 4.0$ & & $\star$ \\
\hline \multicolumn{7}{|l|}{ Arousal } \\
\hline Pre-cigarette & $5.9 \pm 1.2$ & $5.5 \pm 1.1$ & $5.2 \pm 1.2$ & $5.0 \pm 0.8$ & & $\star \star$ \\
\hline Post-cigarette & $6.1 \pm 1.3$ & $5.9 \pm 1.1$ & $5.9 \pm 1.1$ & $6.2 \pm 0.9$ & & \\
\hline Pre-post difference & $0.2 \pm 0.9$ & $0.4 \pm 0.7$ & $0.7 \pm 1.1$ & $1.2 \pm 1.3$ & & $\star \star$ \\
\hline
\end{tabular}

Monotonic polynomial function (two-tail): ${ }^{\dagger} p<0.10,{ }^{\star} p<0.05,{ }^{\star \star} p<0.01$.

\& Lichtenstein, 1990; Carey et al., 1993; Parrott, 1995b). Robinson \& Pritchard (1992) also noted that smokers demonstrate near-normal life-styles and personalities (e.g. compared to many heroin/ cocaine users); but the normality of cigarette smokers is again consistent with the mood normalization explanation. Their other criticism was that nicotine does not induce marked feelings of euphoria (Robinson \& Pritchard, 1992). However, pleasure ratings are increased by smoking and impaired by abstinence (Warburton et al., 1988; West et al., 1989). Furthermore, active smokers report similar levels of pleasure to nonsmokers, whereas deprived smokers report significantly lower pleasure ratings than nonsmokers and non-deprived smokers (Parrott \& Garnham, submitted). Thus smoking does display weak "euphoriant" effects, but again this only reflects mood normalization.

\section{Nesbitt's Paradox resolved?}

Nesbitt (1973) stated that feeling more alert and less stressed after smoking was paradoxical; that it was unusual to be aroused and relaxed. Schachter (1973, p. 148) intriguingly acknowledged: "Perhaps then it's a Paradox, and perhaps it's not". Certainly it has remained a Paradox for many researchers in this field (Dunn, 1978; Gilbert, 1979; Warburton et al., 1988; Ney \& Gale, 1989; Pomerleau \& Pomerleau, 1990, 1992). However, the main reason the Paradox has remained unsolved, is the paucity of research into it. Most smoking research has studied either stress or arousal, but not both together, yet those few studies where they have been monitored in parallel have shown the stress and arousal changes during smoking to be generally independent. This should not be seen as unusual. Personality research has consistently demonstrated that extraversion (cortical arousal) is orthogonal to neuroticism (emotional arousal). Mood questionnaire research has come to similar conclusions. Thus it is perfectly normal to feel mentally alert and relaxed, or tired and irritated, just as it is equally normal to feel alert and tense or sleepy and relaxed. Cortical arousal and emotionality are separate and independent. Nesbitt's Paradox is therefore not actually a paradox; it never was a paradox.

The second question is whether smoking leads to any real gains in stress or arousal (West, 1993). Empirical evidence shows that this does not seem to occur. There is little evidence that smokers are less stressed or more alert than non-smokers (although there is some evidence 
for stimulation under limited conditions). Smokers suffer from abstinence effects, rather than gaining from nicotine use. This explains why smokers try to maintain their nicotine intake in all types of situation, both at work and rest. Regular smokers need nicotine simply to remain normal.

\section{References}

Benowitz, N. L. (1990) Pharmacokinetic considerations in understanding nicotine dependence, in: The Biology of Nicotine Dependence. Ciba Foundation Report, 152 (Chichester, Wiley).

Brown, B. B. (1973) Additional characteristic EEG differences between heavy smokers and nonsmokers, in: DunN, W. L. (Ed.) Smoking Behaviour: motives and incentives (Washington, DC, Winston).

Carey, M. P., Kalra, D. L., Carey, K. B., Halperin, S. \& RichaRds, C. S. (1993) Stress and unaided smoking cessation: a prospective investigation, fournal of Consulting and Clinical Psychology, 61, 831838.

Cattell, R. B. \& Kline, P. (1977) The Scientific Analysis of Personality (New York, Academic Press).

Church, R. E. (1989) Smoking and the human EEG, in: Ney, T. \& GALE, A. (Eds) Smoking and Human Behaviour (Chichester, Wiley).

Cohen, S. \& Lichtenstein, E. (1990) Perceived stress, quitting smoking, and smoking relapse, Health Psychology, 9, 466-478.

Davison, D. \& Parrott, A. C. (1997) Ecstasy (MDMA) in recreational users: self-reported psychological and physiological effects, Human Psychopharmacology, 12, 221-226.

DuNN, W. L. (1978) Smoking as a possible inhibitor of arousal, in: THORNTON, R. (Ed.) International Workshop into the Behavioural Effects of Nicotine (Basel, Karger).

Fant, R. V., Schuh, K. J. \& Stizer, M. L. (1995) Response to smoking as a function of prior smoking amounts, Psychopharmacology, 119, 385-390.

Foulds, J. (1994) Detrimental effects of nicotine on mood? Addiction, 89, 136-137.

Gilbert, D. G. (1979) Paradoxical tranquillizing and emotion-reducing effects of nicotine, Psychological Bulletin, 86, 643-661.

Gilbert, D. G. (1995) Smoking: individual differences, psychopathology, and emotion (London, Taylor and Francis).

Gilbert, D. G. \& Wesler, R. (1989) Emotion, anxiety and smoking, in: Ney, T. \& Gale, A. (Eds) Smoking and Human Behaviour (Chichester, Wiley).

Hasenfrantz, M., Michel. C., Nil, R. \& Battig, K. (1989) Can smoking increase attention in rapid visual processing during noise? Electrocortical, physiological and behavioural effects, Psychopharmacology, 98, 75-80.

Heimstra, N. W., Bancroft, N. R. \& DeKock, A. R. (1967) Effects of smoking upon sustained performance in a simulated driving task, Annals of the New York Academy of Sciences, 142, 295-307.
Heishman, S. J., Taylor, R. C. \& Henningfield, J. E. (1994) Nicotine and smoking: a review of effects on human performance, Experimental and Clinical Psychopharmacology, 2, 345-395.

Hindmarch, I. (1985) The psychopharmacology of clobazam, Royal Society of Medicine International Symposium Series, 74, 3-10.

Hughes, J. R. (1992) Tobacco withdrawal in selfquitters, fournal of Consulting and Clinical Psychology, 60, 689-697.

Hughes, J. R., Higgins, S. T. \& Hatsukami, D. (1990) Effects of abstinence from tobacco, in: Kow Zlowski, L. T., AnNis, H. M. et al. (Eds) Recent Advances in Alcohol and Drug Problems 10 (New York, Plenum).

Hughes, J. R., Higgins, S. T. \& Bickel, W. K. (1994) Nicotine withdrawal versus other drug withdrawal syndromes: similarities and dissimilarities, Addiction, 89, 1461-1470.

IKARD, F. F., GReEN, D. E. \& HoRN, D. (1969) A scale to differentiate between types of smoking as related to the management of affect, International fournal of the Addictions, 4, 649-659.

Jones, M. E. E. \& Parrott, A. C. (1997) Stress and arousal circadian rhythms in smokers and nonsmokers working day and night shifts, Stress Medicine, 13, 91-97.

Keenan, R. M., Hatsukami, D. K. \& Anton, D. J. (1989) The effects of short-term tobacco deprivation on performance, Psychopharmacology, 98, 126-130.

Knott, V. J. \& Venables, P. H. (1977) EEG alpha correlates of nonsmokers, smoking smokers, and smoking deprivation, Psychophysiology, 14, 150-156.

MACKay, C. J., Cox, T., Burrows, G. \& LAzzerini, T. (1978) An inventory for the measurement of selfreported stress and arousal, British fournal of Clinical Psychology, 17, 283-284.

Mathews, G., Jones, D. M. \& Chamberlain, A. G. (1990) Refining the measurement of mood: the UWIST Mood Adjective Checklist, British fournal of Psychology, 81, 17-42.

MCKennel, A. C. (1970) Smoking motivation factors, British fournal of Social and Clinical Psychology, 9, $8-22$.

Nesbitt, P. D. (1973) Smoking, physiological arousal and emotional response, fournal of Personality and Social Psychology, 25, 137-144.

Newhouse, P. A., Sunderland, T., Narang, P. K. et al. (1990) Neuroendocrine, physiologic and behavioral responses following intravenous nicotine in nonsmoking healthy volunteers and in patients with Alzheimer's disease, Psychoneuroendocrinology, 15, 471-484.

Ney, T. \& Gale, A. (1989) The key questions about smoking behaviour, in: NEY, T. \& GALE, A. (Eds) Smoking and Human Behaviour (Chichester, Wiley).

Parrott, A. C. (1992) Smoking and smoking cessation: effects upon human performance, fournal of Smoking-Related Disorders, 3, 43-53.

Parrott, A. C. (1994a) Individual differences in stress and arousal during cigarette smoking, Psychopharmacology, 115, 389-396. 
Parrott, A. C. (1994b) Acute pharmacodynamic tolerance to the subjective effects of cigarette smoking, Psychopharmacology, 116, 93-97.

PARrott, A. C. (1995a) Stress modulation over the day in cigarette smokers, Addiction, 90, 233-244.

Parrott, A. C. (1995b) Smoking cessation leads to reduced stress, but why? International fournal of the Addictions, 30, 1509-1516.

Parrott, A. C. \& Craig, D. (1995) Psychological functions served by nicotine chewing gum, Addictive Behaviors, 20, 271-278.

Parrott, A. C., Garnham, N. J., Wesnes, K. \& PinCock, C. (1996) Cigarette smoking and abstinence: comparative effects upon cognitive task performance and mood state over 24 hours, Human Psychopharmacology, 11, 391-400.

Parrott, A. C. \& Garnham, N. (submitted) Mood and cognitive performance in cigarette smokers, deprived smokers, and non-smokers.

Parrott, A. C. \& Roberts, G. (1991) Smoking deprivation and cigarette reinstatement: effects upon visual attention, fournal of Psychopharmacology, 5, 402-407.

Parrott, A. C. \& Winder, G. (1989) Nicotine chewing gum ( $2 \mathrm{mg}, 4 \mathrm{mg}$ ) and cigarette smoking: comparative effects upon vigilance and heart rate, Psychopharmacology, 97, 257-261.

Perkins, K. A., Grobe, J. E., Epstein, L. H., CagGivla, A. R. \& Stiller, R. L. (1992a) Effects of nicotine on subjective arousal may be dependent on baseline subjective state, fournal of Substance Abuse, 4, 131-141.

Perkins, K. A., Grobe, J. E., Fonte, C. \& Breus, M. (1992b) Paradoxical effects of smoking on subjective stress versus cardiovascular arousal in males and females, Pharmacology Biochemistry and Behavior, 42, 301-311.

Pomerleau, O. F. \& Pomerleau, C. S. (1990) Behavioral studies in humans: anxiety, stress, and smoking, in: The Biology of Nicotine Dependence. Ciba Foundation Symposium, 152, pp. 225-239 (Chichester, Wiley).

Pomerleau, O. F. \& Pomerleau, C. S. (1991) Research on stress and smoking: progress and problems, British fournal of Addiction, 86, 599-604.

Revell, A. (1988) Smoking and performance: a puffby-puff analysis, Psychopharmacology, 96, 563-565.

Robinson, J. H. \& Pritchard, W. S. (1992) The role of nicotine in tobacco use, Psychopharmacology, 108, 397-407 (commentaries: pp. 408-417).

Rosenberg, J., Benowitz, N. L., Jacob, D. \& Wilson, K. M. (1980) Disposition kinetics and effects of intravenous nicotine, Clinical Pharmacology and Therapeutics, 28, 517-522.

Russell, M. A. H., Peto, J. \& Patel, V. A. (1974) The classification of smoking by a factorial structure of motives, Fournal of the Royal Statistical Society, 137, 313-346.

Sahakian, B., Jones, G., Levy, R. Gray, J. \& WarburTON, D. M. (1989) The effects of nicotine on attention, information processing, and short-term memory in patients with dementia of the Alzheimer's type, British fournal of Psychiatry, 154, 797-800.

SCHACHTER, S. (1964) The interaction of cognitive and physiological determinants of emotional state, in: Leiderman, P. H. \& Shapiro, D. (Eds) Psychobiological Approaches to Social Behavior (California, Stanford University Press).

Schachter, S. (1973) Nesbitt's Paradox, in: Dunn, W. L. (Ed.) Smoking Behavior (New York, Wiley).

Schachter, S. (1978) Pharmacological and psychological determinants of smoking, in: THORNTON, R. E. (Ed.) Smoking Behaviour, Physiological and Psychological Influences (Edinburgh, Churchill-Livingstone).

Schechter, M. D. \& RAND, M. J. (1974) Effects of acute deprivation of smoking on aggression and hostility, Psychopharmacologia, 35, 19-28.

SHERwood, N. (1993) Effects of nicotine on human psychomotor performance, Human Psychopharmacology, 8, 155-184.

SHIFFMAN, S. (1982) Relapse following smoking cessation: a situational analysis, fournal of Consulting and Clinical Psychology, 50, 71-86.

SHIFFMAN, S. (1993) Assessing smoking patterns and motives, fournal of Consulting and Clinical Psychology, $61,732-742$.

ShiffMAn, S. \& JARviK, M. E. (1984) Cigarette smoking, physiological arousal, and emotional response: Nesbitt's Paradox re-examined, Addictive Behaviors, 9, 95-98.

Shiffman, S., Paty, J. A., Kassel, J., Gyns, M. \& ZETTLER-SEGAL, M. (1994) Smoking behavior and smoking history in tobacco chippers, Experimental and Clinical Psychopharmacology, 2, 126-142.

Shiffman, S., Paty, J. A., Gyns, M., Kassel, J. A. \& Hickcox, M. (1996) First lapse to smoking: withinsubjects analysis of real-time reports, fournal of Consulting and Clinical Psychology, 64, 366-379.

Silverstein, B. (1982) Cigarette smoking, nicotine addiction, and relaxation, fournal of Personality and Social Psychology, 42, 946-950.

SNyder, F. R. \& HenNingfield, J. E. (1989) Effects of nicotine administration following $12 \mathrm{~h}$ of tobacco deprivation: assessment on computerised performance tasks, Psychopharmacology, 97, 17-22.

SNyder, F. R., Davis, F. C. \& Henningfield, J. E. (1989) The tobacco withdrawal syndrome: assessed on a computerised test battery, Drug and Alcohol Dependence, 23, 259-266.

Speilberger, C. D. (1986) Psychological determinants of smoking behavior, in: Tollinson, R. D. (Ed.) Smoking and Society; towards a more balanced assessment (Lexington, DC Heath).

Surgeon General (1988) Nicotine Addiction (Washington, DC, US Government Printing Office).

Surgeon General (1990) The Health Benefits of Smoking Cessation (Washington, DC, US Government Printing Office).

SwETT, C. (1974) Drowsiness due to chlorpromazine in relation to cigarette smoking, Archives of General Psychiatry, 31, 211-213.

THAYER, R. E. (1978) Factor analytic and reliability studies on the activation-deactivation adjective checklist, Psychological Reports, 42, 747-756.

Warburton, D. M. (1988) The puzzle of nicotine use, in: LAdER, M. (Ed.) The Psychopharmacology of $\mathrm{Ad}$ diction (Oxford, Oxford University Press).

Warburton, D. M. (1992) Smoking within reason, fournal of Smoking-related Disorders, 3, 55-59. 
Warburton, D. M., Revell, A. D. \& Thompson, D. H. (1991) Smokers of the future, British fournal of Addiction, 86, 621-625.

Warburton, D. M., Revell, A. \& Walters, A. (1988) Nicotine as a resource, in: RAND, M. \& Thurau, K. (Eds) The Pharmacology of Nicotine (IRL Press).

Watson, D. \& Tellegen, A. (1985) Towards a consensual structure of mood, Psychological Bulletin, 98, 219-235.

Wesnes, K. \& Parrott, A. C. (1992) Smoking, nicotine and human performance, in: SMITH, A. \& Jones, D. (Eds) Handbook of Human Performance, Vol. II (London, Academic Press).

Wesnes, K. \& Revel, A. (1984) The separate and combined effects of scopolamine and nicotine on human information processing, Psychopharmacology, $84,5-11$.

Wesnes, K. \& Warburton, D. M. (1983) Smoking, nicotine and human performance, Pharmacology and Therapeutics, 21, 189-208.

West, R. J. (1992) The nicotine replacement paradox in smoking cessation: how does nicotine gum really work? British fournal of Addiction, 87, 165-167.

WEST, R. J. (1993) Beneficial effects of nicotine: fact or fiction? Addiction, 88, 589-590 (commentaries: 89, 135-146)
West, R. J. \& HACK, S. (1991) Effect of cigarettes on memory search and subjective ratings, Pharmacology, Biochemistry and Behavior, 38, 281-286.

West, R. J., Hajek, P. \& Belcher, M. (1989) Time course of cigarette withdrawal symptoms while using nicotine gum, Psychopharmacology, 99, 143145.

WeST, R. J. \& JARvis, M. J. (1986) Effects of nicotine on finger tapping rate in non-smokers, Pharmacology, Biochemistry and Behavior, 25, 727-731.

West, R. J. \& Russell, M. A. H. (1985) Preabstinence smoke intake and smoking motivation as predictors of severity of smoking withdrawal symptoms, Psychopharmacology, 87, 334-336.

Westman, E. C., Behm, F. M. \& Rose, J. E. (1996) Dissociating the nicotine and airway sensory effects of smoking, Pharmacology, Biochemistry and Behavior, 53, 309-315.

Wetter, D. W. \& Young, T. B. (1994) The relation between cigarette smoking and sleep disturbance, Preventive Medicine, 23, 328-334.

Wolter, T., Hauri, P. J., Schroeder, D. R. et al. (1997) Effects of 24-hour nicotine replacement on sleep and daytime activity during smoking cessation, Preventive Medicine, in press. 